|Araştırma Makalesi / Research Article|

\title{
Çocuklarda Okul Temelli Yalnızık ve Yaşam Doyumu Arasındaki ilişkide Algılanan Stresin Aracı Rolü
}

\section{The Role of Perceived Stress in the Relationship Between School-Based Loneliness and Satisfaction with Life in Children}

\section{Halil Ekşi ${ }^{1}$, Ayşe Çini ${ }^{2}$, Erdem Sevim ${ }^{3}$}

\author{
Anahtar Kelimeler \\ okul temelli yalnızlık \\ algılanan stres \\ yaşam doyumu \\ çocuklar
}

Keywords
school based loneliness
perceived stress
life satisfaction
children

Başvuru Tarihi/Received
29.12.2019

Kabul Tarihi /Accepted 16.03.2020
Öz

Bu araştırmanın amacı çocuklarda okul temelli yalnızlık ve yaşam doyumu arasında algılanan stresin aracı rolünün incelenmesidir. Bu doğrultuda Kocaeli ili'nde yaşları 9-11 arasında değişen 199'u (\%50,5) kı, 193'ü (\%49) erkek toplam 394 4.sınıf öğrencisi katılmıştır. Veriler Çocuklarda Okul Temelli Yalnızlık Ölçeği, Çocuklar İçin Yaşam Doyumu Ölçeği, Algılanan Stres Ölçeği ve Kişisel Bilgi Formu kullanılarak elde edilmiştir. Verilerin analizinde Pearson analizi, Bağımsız Gruplar T testi, Aracı değişken analizleri ve Bootstrap Analizi kullanılmıştır. Elde edilen bulgulara göre yaşam doyumu ile algılanan stres arasında negatif yönde ; okul temelli yalnızlık ile yaşam doyumu puanları arasında negatif yönde ve algılanan stres ile okul temelli yalnızlık arasında pozitif yönde manidar bir ilişki bulunmuştur .Araştırma sonuçlarına göre okul temelli yalnızlık ile yaşam doyumu arasında algılan stresin kısmi aracılık rolünün istatistiksel olarak anlamlı olduğu görülmektedir. Bundan sonra yapılacak araştırmalarda farklı değişkenler, farklı yaş gruplarında ele alınabilir. Öğrencilerin okul temelli yalnızlık ve olası stres kaynakları araştırılarak psikoeğitim programları geliştirilebilir.

\section{Abstract}

The aim of this study is to examine the mediating role of perceived stress among school-based loneliness and life satis-faction in children. In this direction, 199 (50.5\%) girls and 193 (49\%) boys were 392 grade 4 students. Data were obtained by using the School Based Loneliness Scale in Children, Life Satisfaction Scale for Children and Perceived Stress Child Form and Personal Information Form. In the analysis of the data ; Pearson analysis, Independent Groups T test, Tool variable analysis and Bootstrap Analysis were used. According to the findings, there was a negative correlation between life satisfaction and perceived stress; there was a negative corre-lation between school-based loneliness and life satisfaction scores, and a significant positive correlation between perceived stress and school-based loneliness. According to the results of the study, the partial mediating role of perceived stress between school-based loneliness and life satisfaction is statistically significant. In future researches, different variables can be handled in different age groups. Psychoeducation programs can be developed by researching students' school-based loneliness and possible sources of stress.

\footnotetext{
${ }^{1}$ Marmara Üniversitesi Atatürk Eğitim Fakültesi Rehberlik ve Psikolojik Danışmanlık, İstanbul, TÜRKiYE; https://orcid.org/0000-0001-7520-4559

2 MEB, Şehit Hacı Uzun Ilkokulu, Sakarya, TÜRKIYE; https://orcid.org/0000-0001-9434-002X

${ }^{3}$ Marmara Üniversitesi Atatürk Eğitim Fakültesi Rehberlik ve Psikolojik Danışmanlık, İstanbul, TÜRKiYE; https://orcid.org/0000-0002-8887-6060
}

Alıntı/Citation: Ekşi, H., Çini, A., \& Sevim, E. (2020). Çocuklarda okul temelli yalnızlık ve yaşam doyumu arasındaki ilişkide algılanan stresin aracı rolü. Kastamonu Education Journal, 28(3), 1460-1470. doi: 10.24106/kefdergi.4128 
Extended Abstract

\section{Introduction}

Life satisfaction includes a multifaceted satisfaction with both the person (what they do, what they put forward) and the environment (family, friends) (Suldo, Riley \& Shaffer, 2006). Childhood and adolescence are critical for life satisfaction in adulthood (Civitci, 2014). There are many factors affecting life satisfaction. One of them is loneliness. It is considered as multidimensional (emotional, cognitive and relational) in single children (Hymel, Tarulli, Hayden Thomson \& Terrell-Deutsch, 1999). (2001). As the level of loneliness increases, life satisfaction decreases in students. This is an important risk factor in children (Kemala, 2017). Relationships established in school environment and social skills are a prerequisite for children to acquire life skills (Hartup \& Stevens, 1997). (Mellor, Stokes, Firth, Hayashi \& Cummins, 2008), social anxiety Weeks, Coplan \& Kingsbury (2009) depression (DiTommaso \& Spinner, 1997), low academic performance (Shin, 2007) is observed. The perceived stress level in children is increasing (Natvig, Albrektsen \& Qvarnstrqm, 2003). and research, preventive / preventive in terms of anxiety, depression In terms of peer relations, academic performance is intervening. Childhood experiences constitute a person's life diagram. School experiences during this period will be decisive in one's personal / social and educational development during adulthood. In an environment where a child who spends most of the day at school feels alone, impairments in life functionality will occur. Academic performance, family and peer relationships of a child whose life satisfaction decreases and stress level increases, will be negatively affected. When we examine the literature, there is a lack of research and importance regarding the relationship between school-based loneliness and life satisfaction.

\section{Method}

Structural equality research model is the research that aims to investigate the mediating effect of perceived stress in the relationship between school-based loneliness and life satisfaction in children. The population of the study consisted of 3944 th year students (50.8\%) and 193 (49.2\%) boys whose ages ranged from 9-11 (50.8\%) reached by stratification sampling in Kocaeli province in 2018-2019 academic year. As data collection tool; Personal Information Form, School Based Loneliness Scale in Children adapted by Kaya (2005), Life Satisfaction Scale for Children adapted by Altay and Ekşi (2018), and Perceived Stress Scale in Children (8-11 years) adapted by Oral and Ersan (2017). SPSS 21.0 and AMOS 20.0 programs were used to analyze the data. Pearson analysis, Independent Groups T test, Tool variable analysis and Bootstrap Analysis were performed.

\section{Result and Discussion}

According to the findings of the study, there was a negative correlation between the scores obtained from the life satisfaction scale and the scores obtained from the stress scale $(r=-, 26)$; A statistically significant negative correlation was found between the scores obtained from the life satisfaction scale and the scores obtained from the school-based loneliness scale $(r=-, 31)$. A statistically significant correlation was found between perceived stress scale scores and school-based loneliness scale scores $(r=, 36)$. The direct effect of school-based loneliness scores on life satisfaction scores is -.31. When the perceived stress variable is included in the model of the relationship between school-based loneliness and life satisfaction, it is seen that the direct effect of school-based loneliness on life satisfaction is at -, 25 level and indirect effect -, 06 level. Estimation intervals were examined to determine whether the indirect effect was significant and the partial mediating role of perceived stress between school-based loneliness and life satisfaction was significant. The direct effect of school-based loneliness scores on perceived stress scores was 36; The direct effect of perceived stress variable scores on life satisfaction scores is -, 17 . In the established model, $12 \%$ of the total variance of the life satisfaction variable is explained, and $13 \%$ of the total variance of the perceived stress variable is explained. According to the results of the study, the perceived stress scale scores differ significantly in favor of the students who change school. Uluocak (2009) similarly suggested behavioral problems and stress precursors in children during school change. Life satisfaction scores are in favor of female students; It was seen that perceived stress scale scores differed statistically in favor of male students. In parallel with this finding, it was demonstrated by a school-age research (Strózik, Strózik \& Szwarc, 2016). School-based loneliness scale scores do not differ according to the gender variable. In support of this finding, it is seen that differentiation starts with adolescence period (Rotenberg, MacDonald \& King, 2004). In the research, it is seen that life satisfaction increases as socioeconomic level increases. There are studies supporting this finding (Seligson, Huebner \& Valois, 2003; Tuzgöl Dost, 2007). For the main purpose of the study, a statistically significant negative correlation was found between the scores obtained from the life satisfaction scale and the scores obtained from the stress and school-based loneliness scales. A statistically significant relationship was found between the perceived stress scale scores and the school-based loneliness scale scores. the negative correlation between life satisfaction (Bozorgpour \& Salimi, 2012) is consistent with the literature. 
GiRiş

Yaşam doyumu kavramı, literatürde psikoloji alanında sıklıkla ele alınan kavramlardan biridir (Adams, 1969; Neugarten, Havighurst \& Tobin, 1961; Pavot \& Diener, 2009). Pozitif psikoloji müdahalesi (Seligman \& Csikszent-mihalyi, 2014), çocuklara olumlu bilişlerini, duygularını ve davranışlarını artırmanın yollarını öğrettiğinden, çocukların mevcut duygusal problemlerle başa çıkmasına, gelecekteki stres ve olumsuzluklarla başa çıkma yeteneklerini geliştir-melerine yardımcı olabilir (Kwok, Gu \& Kit, 2016).

Yaşam doyumu, insanların bir bütün olarak yaşamlarından memnuniyetlerini göz önüne alırken yaptıkları veya aile, çevre, arkadaşlar ve benlik gibi yaşamın belirli alanları ile ilgili olarak bilişsel, küresel bir değerlendirme olarak tanımlanır. Yaşam memnuniyeti daha çok bütünlük içeren organize bir bileşendir (Suldo, Riley \& Shaffer, 2006). Yaşam doyumu, kişinin belirli alanlardan memnuniyetlerini özetlemek yerine, yaşamlarını genel olarak değerlendirmel-eridir (Diener, Emmons, Larsen \& Griffin, 1985). Bireyin yetişkin yaşamında psikososyal olarak çok yönlü gelişiminde kritik olan çocukluk ve ergenlik dönemi göz önüne alındığında, yaşam doyumu ile ilişkili etmenlerin de erken yaşlarda incelenmesi gerekli görülmektedir (Civitci, 2014). Bu etmenlerden birisi de yalnızlıktır.

Çocukların yalnızlığı üç boyutta ele alınmaktadır: Duygusal, Bilişsel ve Kişilerarası iliş̧kiler. Duygusal boyut: duy-gusal koşullar (üzüntü, sıkıntı, acı). Bilişsel boyut: Arkadaşık, katılım, duygusal destek, sevgi, güvenilir birlik, değer artırma, besleme fırsatı (hayvan bakımı gibi).Kişilerarası ilişkiler boyutu: Fiziksel ayırma ve psikolojik uzaklaşma olarak ikiye ayrılır. Fiziksel ayırma; kayıp (arkadaşının taşınması gibi), alt-üst olma, geçici yokluktur. Psikolojik Uzak-laşma; anlaşmazlık, reddedilme, bağlılığın bozulması, dışlanma, görmezden gelinmek olarak açıklanmaktadır (Hymel, Tarulli, Hayden Thomson \& Terrell-Deutsch, 1999).

Yaşam doyumunun önemli bir göstergesi yalnızlıktır. Genel olarak, yalnız insanlar daha düşük yaşam doyumu oranları bildirmektedir (Goodwin, Cook \& Yung, 2001). Yapılan çalışmalardan elde edilen veriler yalnızlığın ; düşük benlik saygısı (Boivin, Hymel ve Bukowski, 1995), intihar (Wenz, 1977), akademik başarı (Yıldırım, 2000), akademik uyum, olumsuz başa çıkma (Quan, Zhen, Yao \& Zhou, 2014), depresyon (Qualter, Brown, Munn \& Rotenberg, 2010), düşük özsaygı (Ouellet \& Joshi, 1986), alkolizm (Allen, Peterson \& Whipple, 1981) gibi pek çok konu ile ilişkili olduğunu ortaya koymaktadır.

Yalnızlık, sosyal bir eksiklik olarak değerlendirilebilir. Yalnızık, bir kişinin sosyal ilişkiler ağının kişinin istediğinden daha küçük ya da daha az tatmin edici olduğunu göstermektedir (Peplau \& Perlman, 1979; Weiss, 1974). Yaygın olarak "yalnızlığı" temsil eden bireylerin temelde ortak deneyimler yaşadığına inanılmaktadır (Russell, Cutrona, Rose \& Yurko,1984). Yalnızlık duygusal ve sosyal izolasyon olmak üzere iki ayrı biçimde deneyimlenmektedir. Yalnızlık; boşluk, endişe, huzursuzluk ve marjinalite duyguları ile tanımlanmıştır (Weiss,1973). Duygusal yalnızlığın, sosyal yal-nızlıktan ziyade yaşam doyumunda daha güçlü bir negatif yordayıcı olduğu da görülmektedir (Salimi, 2011).

Sosyal yaşamın sürdürülmesi güçlü bir şekilde yaşam doyumunu etkilemektedir. Bu nedenle yalnızlık sorunu, öğrencilerin hem şimdiki yaşam hem de gelecekteki yaşamlarında, yaşam doyumlarına karşı bir tehdit oluşturmaktadır (Kemala,2017). Algılanan izolasyon ; doyumsuz, karamsar ve isteksiz bir yaklaşım oluşturabilir. Bu da diğerleriyle ilişki kurma konusunda daha az çaba harcamasına ve etkin girişimlerde bulunmamasına neden olabilir (Jones, Freemon ve Goswick, 1981). Asher, Hymel ve Renshaw (1984), çocuklarla akran ilişkileri ile yaşam doyumu arasındaki ilişkiyi inceledikleri araştırmalarında örneklem grubunu oluşturan çocukların \%10'nun yalnızlık ve sosyal doyumsuzluk duygularını yaşadıklarını bulgulamışlardır.

Gelişim dönemi özellikleri göz önüne alındığında çocukluk çağında sosyal ilişkiler büyük önem taşımaktadır. Çocukların ebeveynleri ile kurdukları ilişki kadar akranları ile kurdukları ilişki de psikososyal gelişimine katkı sağla-makta ya da güçleştirerek zarar vermektedir. Bu deneyim sağlıklı bir şekilde gerçekleşmediğinde; çocuğun saldırganlık, uyum sağlayamama ya da sosyal izolasyon şeklinde davranış örüntüleri ortaya çıkmaktadır. Akran kabulü, sosyal benzerlik gibi faktörler ile sosyal becerilerinin geliştirilmesi, sürdürülmesi ve ilerleyen yaşlarına örnek teşkil etmesi beklenmektedir (Vasta, Haith \& Miller, 1992).

Arkadaşlıklar, sosyal gelişim ve adaptasyondaki diğer (eksik) ilişkilerin yerini alabilir. Olumlu arkadaşlık ilişkileri yaşanan stres, gerginlikleri ve kayıpların etkilerini hafifleten koruyucu faktörler veya "tamponlar" dır (Hartup \& Ste-vens, 1997).

Yapılan araştırmalar, bir çocuğun sosyal dünyayla başa çıkmadaki etkinliğinin büyük ölçüde yakın ilişkiler ko-nusundaki deneyimden kaynaklandığını göstermiştir (Hartup, 1989). Çocukların yaşadığı birçok ayrılık, yetişkinlerin hâkim olduğu bir dünyada hissettiği güçsüzlük, kısıtlayıcı öğrenme ortamı ile okulun sık sık verdiği zarar, çocukların akranlarının kötü davranışları, spor ve dış görünüşün önemli hale gelmesi çocukların yalnızlık ile mücadelelerini etkilemektedir (Tuck, 1981). Bazı spesifik davranış problemleri ve akademik zorlukları olan çocukların, okuldaki yoğun yalnızlık duygularını kabul etme eğiliminde olduğu görülmektedir (Galanaki, Polychronopoulou \& Babalis, 2008).

Çocukların yalnızlık ve sosyal doyumsuzluk raporlarını içeren analizler, çocukların arkadaşlık uyumunun çocukların yalnızlık duyguları üzerinde etkisi olduğunu göstermektedir. Bu etki akran grubu kabulünün etkisinin de ötesinde, arkadaşlık kurma ile grup kabulü arasındaki sistemin önemini göstermiştir (Parker \& Asher, 1993). Ayrıca sınıfta yakın arkadaşlık kuramayan çocukların daha fazla yalnızlık yaşadıklarını göstermektedir. Ek olarak, akran kabulünün arkadaşsız çocuklara yalnızlığa karşı bir tampon sağladığını göstermektedir (Renshaw, \& Brown,1993).

Okul, çocukların mutluluğunun okuldaki becerilerine dayandığı sosyal bir bağlam oluşturur (Chang, McBride-Chang, Stewart, \& $\mathrm{Au}, 2003$ ). Aidiyet gereksinimlerinin karşılanamaması sosyal izolasyon, yabancılaşma ve yalnızlık duygularına yol açabilir. (Mellor, Stokes, Firth, Hayashi \& Cummins, 2008). Sosyal yalnızlık, depresyonun en büyük göstergesidir (DiTommaso \& Spinner ,1997). Okul ortamında yalnızlık hisseden öğrenciler, sınıf ortamının kalitesini daha düşük olarak değerlendirmektedir. Bu öğrencilerin okul 
çalışmalarına ve etkinliklerine daha az düzeyde katılım gösterdikleri ve daha düşük not ortalmasına sahip olduğu görülmektedir (Dobson, Campbell \& Dobson, 1987).

Yoğun stres deneyimi, mutluluk hissini önemli ölçüde azaltmaktadır. Öğretmenlerin sosyal desteği de mutluluğu önemli ölçüde arttırmaktadır. Ayrıca mutlu öğrenciler mutsuz olduğunu bildiren öğrencilere göre çok daha fazla akran desteğine sahip olduğu görülmektedir (Natvig, Albrektsen \& Qvarnstrqm, 2003).

Roffey ve arkadaşları (1994), daha az sosyal yetenekli öğrencilere daha fazla dışa dönük ve sosyal yönden duyarsız öğrencilerin egemen olabileceğine dikkat çekmektedir. Ayrıca, birçok öğrencinin birlikte çalışırken ya da birbirlerinin ortamlarında vakit geçirirken, grup tarafından yapılan ihmal veya aktif ayrımcılık sonucu yalnız bırakılması da olağandır. Yalnız öğrenciler bu tür günlük izolasyonu endişe ile deneyimlemekteler. Öyleyse, bir sosyal ortam olan okul, öğrencilerin duygusal ve sosyal gelişimlerini engelleyen önemli bir olumsuz faktör olabileceği açıktır (akt. Laine, 1998).

Weeks, Coplan \& Kingsbury (2009) çocuklarda yaptığı bir araştırmada sosyal anksiyete yaşayan çocukların yaşa-mayanlara göre manidar biçimde daha fazla yalnızlık yaşadığını göstermektedir. Ayrıca okulu daha az beğendiklerini ve okuldan kaçındıklarını da ortaya koymaktadır.

Shin (2007) 'e göre yalnız çocukların daha fazla kendilerini geri çektikleri ve akademik performanslarının daha düşük olduğu ve bu durumun cinsiyet ile bağlantılı olmadığı görülmektedir. Ayrıca yalnızlık arttıkça arkadaşlık ilişkilerinin (algılanan dostluk kalitesi düzeyi, akran kabulü ve arkadaş sayısı) azaldığı görülmektedir.

Yalnızlık, çeşitli gençlik problemi alanlarıyla ilişkili önemli ve ilgili bir deneyim olarak kabul edilmektedir. Hem araştırmacılar, klinisyenler hem de okul danışmanları tarafından bu konudaki ilginin artması muhtemel olumlu etkilerin doğmasına sebep olabilecektir. Bu üzücü ve karmaşık örüntüyü anlayarak; okul ortamlarında kaygı ve depresyon arasındaki etkileşimi çözerek daha fazla dikkat çekilmesi ve farkındalık oluşturulması gerekmektedir (Ebesutani, Fierstein, Viana, Trent, Young \& Sprung, 2015).

Okul temelli uygulamalar, çocukların içinde bulunduğu ortamları değiştirme ve düzenleme imkanı sağlamaktadır. Böylece düzenlemeye teşvik etmek ve müdahale için yeni yollar oluşturma fırsatı sunmaktadır. Okul temelli uygulamaların, hem çevresel hem de bireysel katılımcıların gelişimine olumlu bir şekilde katkı sunması ve rehberlik etmesi önemlidir (Baker, Dilly, Aupperlee \& Patil, 2003).

Çocukluk dönemindeki deneyimler kişinin yaşama dair şemalarını oluşturmaktadır. Bu dönemdeki okul deneyimleri kişinin yetişkinlik döneminde kişisel/sosyal ve eğitsel gelişiminde belirleyici olacaktır. Günün büyük bir bölümünü okulda geçiren bir çocuğun yalnız hissettiği bir ortamda yaşam işlevselliğinde bozulmalar meydana gelecektir. Yaşam doyumu azalan ve stres düzeyi artan bir çocuğun akademik performansı, aile ve akran ilişkileri olumsuz etkilenecektir. Literatürü incelediğimizde okul temelli yalnızıı ve yaşam doyumu arasındaki ilişkiye dair araştırma eksikliği ve önemi görülmektedir. Tüm bu durum göz önüne alındığında çocukların okul temelli yalnızlıkları ve yaşam doyumları arasındaki ilişkide algılanan stresin aracılık ettiği düşünülmektedir. Bireyin yaşadığı yalnızlık, algıladığı stres, yaşam doyumunda belirli bir etkiye sahiptir. Bu sebeple bu çalışmada çocuklarda okul temelli yalnızlık ile yaşam doyumu arasındaki ilişkide algılanan stresin aracı rolünün incelenmesi amaçlanmaktadır.

\section{YÖNTEM}

\section{Araştırma Modeli}

Çocuklarda okul temelli yalnızlık ve yaşam doyumu arasındaki ilişkide algılanan stresin aracılık etkisini incelemeyi amaçlayan araştırmanın modeli yapısal eşitlik araştırma modelidir.

Yapısal eşitlik modellemesi bağımsız değişkenden aracıya ve aracı değişkenden sonuca (bağımlı değişken) olmak üzere çoklu ilişkileri, görünen, gizil değişkenleri modelleyerek inceleyebilmektedir (Hoyle \& Gottfredson, 2015). Yapı üzerinde ayrıntılı çalışma yapılması, karşılaştırmalar, yol katsayıları ile derinlemesine inceleme fırsatı sunmaktadır (Hoyle \& Smith, 1994). Çoklu regresyon, yol çözümlemesi ve doğrulayıcı faktör çözümlemesi YEM'in yapısını oluştururken (Tezcan, 2008), nedensel yönü belirlenmiş ilişkiler (doğrudan, dolaylı) ve yönü olmayan ilişkilerin (yapısal korelasyon) modelinin sınanmasını temel almaktadır (Sümer, 2000).

\section{Evren ve Örneklem}

Araştırmanın evrenini Kocaeli ilinde 2018-2019 eğitim öğretim yılında öğrenim görmekte olan 4.sınıf öğrencileri oluşturmaktadır. Bu kapsamda 429 öğrenciye ulaşılmıştır. Gerekli değerlendirmelerden sonra 394 katılımcıya yönelik olarak verileri ile analiz yapılmıştır. Tabakalama örnekleme yöntemi ile farklı sosyoekonomik düzeyler gösteren altı farklı okul belirlenmiş ve bu okullar bünyesinde küme örnekleme yöntemi ile 4.sınıf düzeyinde üç sınıf olacak şekilde yaşları 9-11 arasında değişen 199'u $(\% 50,8)$ kız, 193'ü $(\% 49,2)$ erkek toplam 394 ilkokul öğrencisi örneklem grubuna seçilmiştir.

Araştırmada örneklem grubunu oluşturan katılımcıların 199'u $(\% 50,8)$ kız, 193'ü $(\% 49,2)$ erkektir. Katılımcıların sosyoekonomik durumu incelendiğinde; katılımcılardan 15'i $(\% 3,9)$ düşük, 300'ü $(\% 78,7)$ orta, 66'sı $(\% 17,3)$ yüksek durumdadır. Katılımcıların 280'i $(\% 72,7)$ yürüyerek, 56'sı (\%14,5) araba, 49’u (\%12,7) servis ile okula gelmektedir. Katılımcıların 113'ü $(\% 28,7)$ okul değişimi yapmış, 281'i $(\% 71,3)$ okul değişimi yapmamıştır. Ayrıca tabloda yer verilmeyen bazı betimsel istatistikler şu şekildedir: Katılımcıların 391'inin $(\% 99,2)$ annesi hayatta, 3'ünün $(\% 0,8)$ hayatta değildir. 388'inin (\%99) babası hayatta, 4'ünün (\%1) hayatta değildir. Katılımcıların anne eğitim durumları ise $125^{\prime}$ i $(34,4)$ ilkokul, 90’ı $(24,8)$ ortaokul, 91'i $(25,1)$ lise ve 57 'si $(15,7)$ lisans ve üstü şeklindedir. Baba eğitim durumları ise 69'u (19,1) ilkokul, 102'si $(28,3)$ ortaokul, 101'i (28) lise ve 89'u $(24,7)$ lisans ve üstü 
şeklindedir. Öğrencilerin 369'unun $(\% 94,4)$ anne babası birlikte, $22^{\prime}$ sinin $(\% 5,6)$ boşanmıştır. Kardeş sayıları incelendiğinde ise; 43'ünün (\%11) 1, 156'sının $(39,8) 2$, 114'ünün $(\% 29,1) 3$ ve 79'unun $(\% 20,2) 4$ ve daha fazladır. Öğrencilerin 310'unun (\%79,1) odası varken, $82^{\prime}$ sinin $(\% 20,9)$ odası yoktur. Öğle arası beslenme alışkanlıkları ise; 142 'si $(\% 36,7)$ evde yemek yer, 18'i $(\% 4,7)$ yemekhaneye gider, 117 'si $(30,2)$ evden yemek getirirken, $110^{\prime} \mathrm{u}(28,4)$ kantinde yemek yemektedir.

\section{Veri Toplama Araçları}

\section{Kişisel Bilgi Formu}

Öğrencinin demografik özelliklerini belirlemek için oluşturulan formda; yaş, cinsiyet, sosy-oekonomik düzey, anne-baba genel ve eğitim durumu, kardeş sayısı, okul değişikliği, evde odasının olup olmaması, beslenme alışkanlığı ve okula ulaşım şeklini içeren sorular sunularak değişkenlere yer verilmiştir. Bu değişkenlerin yaşam doyumu, okul temelli yalnızlık ve yaşam doyumu ile ilişkisi incelenmiştir.

\section{Çocuklarda Okul Temelli Yalnızlık Ölçeği}

Asher ve Wheeler (1985)'in çocuklar için yalnızlık ölçeğinin Türkçe'ye uyarlanmasına uzman görüşleri alınarak okul temelli hale getirilmiştir. Ölçeğin orijinal hali 3-6. sınıflar arasındaki öğrencilere uygulanırken bu çalışmada 3-8. Sınıfa devam eden 1683 öğrenci örneklem olarak seçilerek uygunluğu incelenmiştir. Ölçekte 16 asıl, 8 dolgu maddesi ile toplam 24 madde bulunmaktadır. Dolgu maddeleri çocukların hobi ve ilgilerini içermektedir ve ölçek puanlamasına dahil edilmemektedir. Ölçekte çocukların her bir madde için 5'li likert tipinde tepkilerini göstermesi beklenmektedir. Dereceler ise; (1) "Benim için her zaman doğru", (2) "Benim için çoğunlukla doğru", (3) "Benim için bazen doğru", (4) "Benim için doğru değil" ve (5) "Benim için hiç doğru değil” şeklinde oluşmaktadır. Ölçekte bazı maddeler tersinden puanlanmaktadır. Ölçekten alınabilecek puan 16 ile 80 arasında değişmektedir. Ölçekten alınan puanının artması yaşanan yalnızlık duygusunun arttığını göstermektedir. Ölçeğin iç tutarlık katsayısı 3-4 sınıflar için .87, test-tekrar test yöntemi ile güvenirlik katsayısı .76 olarak hesaplanmıştır (Kaya, 2005). Mevcut araştırmada Çocuklarda Okul Temelli Yalnızlık Ölçeği Cronbach Alfa iç tutarlılık güvenirlik katsayısı .80 olarak hesaplanmıştır.

\section{Çocuklar İçin Yaşam Doyumu Ölçeği}

Gadermann, Schonert-Reichl, ve Zumbo (2009) tarafından geliştirilen ölçek gerekli çeviri çalışmalarının ardından 8-13 yaş arasında 440 öğrenciye uygulanarak uyarlanmıştır. Yapılan doğrulayıcı faktör analizi ile tek boyutlu yapısı uygun görülen ölçek 5 'li dereceleme sisteminde 5 sorudan oluşur. Dereceler ise; Hiç katılmıyorum 1, Çok katılmıyorum 2, Kararsızım 3, Biraz Katılıyorum 4 , Tamamen katılıyorum 5 şeklindedir. Ölçek toplam puanı arttıkça çocuğun yaşam doyumunun da artması beklenmektedir. Ölçeğin iç tutarlılık güvenirlik katsayısı 0.792 'dir. Ölçek madde toplam puan korelasyon katsayıları ise 0.569 ile 0.745 arasında değişmektedir (Altay \& Ekşi, 2018). Mevcut araştırmada elde edilen veriler doğrultusunda Çocuklar için Yaşam Doyumu Ölçeği Cronbach Alfa iç tutarlılık güvenirlik katsayısı .64 olarak hesaplanmıştır.

\section{Çocuklarda (8-11 yaş) Algılanan Stres Ölçeği}

Snoeren-Hoefnagels (2014) geliştirilen ölçeğin uzman görüşleri alınarak Türkçe'ye uyarlama çalışması 380 öğrenci ile oluşturulan örnekleme uygulanması ile yapılmıştır. Çocukların geçen haftayı $4^{\prime}$ lü dereceleme sisteminde değerlendirmeleri beklenmektedir. Bu dereceleme ise; "hiç", "bazen”, "sık sık", "her zaman” şeklinde tepkiler verebileceği 9 maddeden oluşmaktadır. Ölçekten alınan puan toplamı ile çocuğun stres düzeyi doğru orantılıdır. Ters madde bulunmayan ve tek boyutlu olan ölçekte alınabilecek puan toplamı en düşük 0 puan ve en yüksek 27 puandır. Ölçeğin Cronbach Alfa iç tutarlılık güvenirlik katsayısı .76 ve test-tekrar test korelasyonu .71 olarak hesaplanmıştır. Ölçeğin düzeltilmiş madde-toplam korelasyon katsayıları .34 ile .54 arasında değişmektedir (Oral \& Ersan, 2017). Mevcut araştırmada elde edilen veriler doğrultusunda Çocuklarda Algılanan Stres Ölçeği'nin Cronbach Alfa iç tutarlılık güvenirlik katsayısı .69 olarak hesaplanmıştır.

\section{işlem}

Araştırma verileri, Çocuklarda Okul Temelli Yalnızlık, Yaşam Doyumu ve Algılanan Stres ölçeklerinin ve kişisel bilgiler formu veri toplama araçlarının 4.Sınıf öğrencilerine uygulanması ile elde edilmiştir. İşlem öncesinde veli ve kurumda gerekli izinler alınmıştır. Uygulama sırasında öğrencilerin kimlik bilgileri yazmalarına gerek olmadığı, verilen cevapların gizli tutularak sadece araştırma amacıyla kullanılacağı belirtilerek katılımcıların doğru ve eksiksiz bilgiler vermeleri istenmiştir. Verilerin analizinde SPSS 21.0 ve AMOS 20.0 programları kullanılmıştır. Pearson analizi, Bağımsız Gruplar T testi, Aracı değişken analizleri ve Bootstrap Analizi yapılmıştır.

\section{BULGULAR}

Ölçeklerden elde edilen puanların cinsiyet, okul değişimi, okula geliş ve sosyoekonomik düzey gibi değişkenlere göre farklılaşıp farklılaşmadığını belirlemek için fark testleri gerçekleştirilmiştir. Grupların normal dağılımı söz konusu iken parametrik fark testleri (Bağımsız gruplar t Testi ve One-Way ANOVA), grupların dağılımı normal değilse non-parametrik fark testleri (Kruskall Wallis - H) testi yapılmıştır. 
Tablo 1. Cinsiyet, okul değişimi, okula geliş ve SED değişkenlerine ilişkin puanların gruplara göre farklılaşıp farklılaşmadığına ilişkin Bağımsız gruplar t Testi, One-Way ANOVA ve Kruskall Wallis - $\mathrm{H}$ Testi analizi sonuçları

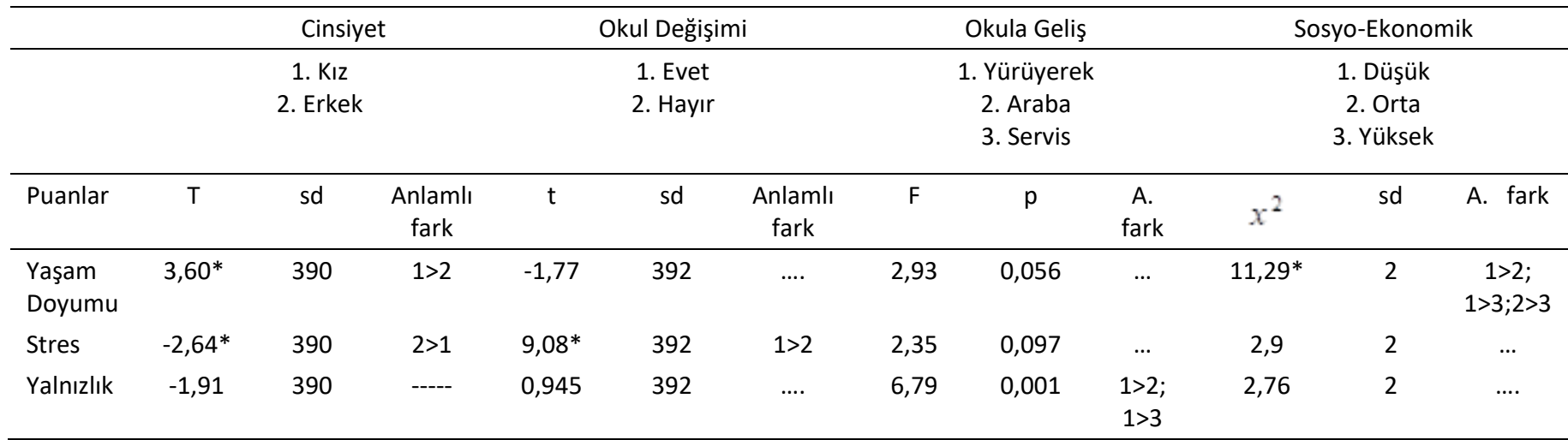

${ }^{*} p<, 05$

Yaşam doyumu, algılanan stres ve okul temelli yalnızlık ölçekleri puanlarının cinsiyet değişkeni ve okul değişimi olup olmadığına göre farklılaşıp farklılaşmadığını belirlemek için Bağımsız gruplar t Testi; okula nasıl geldikleri değişkenine göre farklılaşıp farklılaşmadığını belirlemek için One -Way ANOVA ve son olarak algılanan gelir düzeyi değişkeni için de Kruskall Wallis -H testi gerçekleştirilmiştir. Tablo incelendiğinde yaşam doyumu puanlarının kız öğrencilerin lehine; algılanan stres ölçeği puanlarının erkek öğrencilerin lehine istatiksel açıdan farklılaştığı görülmektedir ( $p<.05)$. Okul temelli yalnızlık ölçeği puanlarının ise cinsiyet değişkenine göre farklılaşmadığı görülmektedir ( $p>.05)$.

Okul değişimi değişkenine göre yaşama doyumu ölçeği puanları ile okul temelli yalnızlık ölçeği puanlarının anlamlı düzeyde farklılaşmadığı görülmektedir ( $p>$.05). Ancak algılan stres ölçeği puanlarının okul değişimi yapan öğrencilerin lehine olacak şekilde anlamlı düzeyde farklılaşmaktadır $(p<.05)$.

Okula nasıl ulaşım sağladıkları değişkenine göre ise sadece okul temelli yalnızlık ölçeği puanları anlamlı düzeyde farklılaştığı görülmektedir. Bu farklılık ise okula yürüyerek gelenler ile servis ile gelenler arasında servisle gelenlerin lehine, yine okula yürüyerek gelenlerle ile araba ile gelenler arasında araba ile gelen grubun lehine anlamlı düzeyde farklılaşmaktadır.

SED değişkenine göre ise yapılan Kruskal Wallis- $\mathrm{H}$ testi sonuçlarına göre sadece yaşam doyumu ölçeği puanları anlamlı düzeyde farklılaşmaktadır. Bu farklılık düşük ile orta grup arasında orta grup lehine, düşük ile yüksek grup arasında yüksek lehine ve orta gelir grubu ile yüksek gelir grubu arasında yüksek gelir grubuna dahil olan öğrencilerin lehine anlam düzeyde farklılaşmaktadır $(p<.05)$.

Tablo 2. Yaşam Doyumu Ölçeği, Algılanan Stres Ölçeği ile Okul Temelli Yalnızlık Ölçeğinden alınan puanlar arasındaki ilişkiyi belirlemek üzere yapılan Pearson Çarpım Moment Korelasyon Analizi sonuçları

\begin{tabular}{lccc}
\hline Değişkenler & Yasam doyumu & Stres & Yalnızlık \\
\hline Yasam doyumu & 1 & & \\
Stres &,$- 256^{*}$ & 1 & $1356^{*}$ \\
Yalnızlık & $-0,309^{*}$ & & 1 \\
\hline${ }^{*}<<001$ & &,
\end{tabular}

Tablo 2'de görüldüğü üzere yaşam doyumu ölçeğinden alınan puanlar ile stres ölçeğinden alınan puanlar arasında negatif yönde ( $r=-, 26)$; yaşam doyumu ölçeğinden alınan puanlar ile okul temelli yalnızlık ölçeğinden alınan puanlar arasında yine negatif yönde ( $r=-, 31)$ istatiksel açıdan anlamlı bir ilişki bulunmuştur ( $p<.001)$. Algılanan stres ölçeği puanları ile okul temelli yalnızlık ölçeği puanları arasında pozitif yönde $(r=, 36)$ istatiksel açıdan anlamlı bir ilişki bulunmuştur $(p<.001)$.

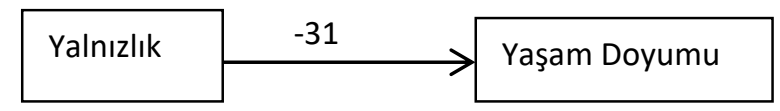

Şekil 1.

Şekil 1'de Okul temelli yalnızlık ile yaşam doyumu arasındaki ilişkide algılan stres değişkeninin rolü incelenmeden önce okul temelli yalnızlık puanlarının yaşam doyumu puanlarına doğrudan etkisi değerlendirilmiştir. Bu sonuca göre okul temelli yalnızlık

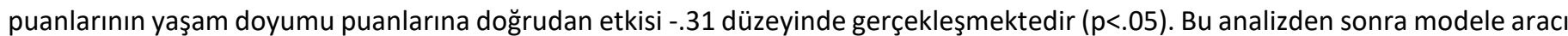
rolü olarak algılanan stres değişkeni dahil edilmiş ve model test edilmiştir. Analiz sonuçları şekil 2'de verilmiştir. 


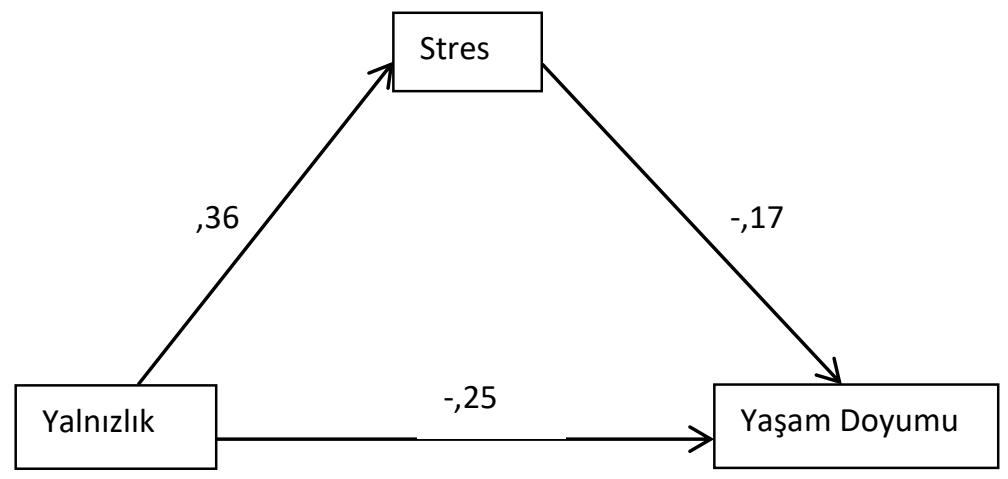

\section{Şekil 2.Kuramsal model}

Şekil 2 incelendiğinde, okul temelli yalnızlık ile yaşam doyumu arasındaki ilişki modeline algılanan stres değişkeni dahil edildiğinde okul temelli yalnızlığın yaşam doyumu üzerindeki doğrudan etkisinin .06 'lik düşüş yönünde değişim göstermektedir. Bu doğrultuda algılanan stres değişkeni modele dahil edildiğinde okul temelli yalnızlığın yaşam doyumu üzerindeki doğrudan etkisi -,25 düzeyinde ve dolaylı etkisi -,06 düzeyinde olduğu görülmektedir ( $p<.05)$. Okul temelli yalnızlık puanlarının algılanan stres puanlarına doğrudan etkisi ,36 düzeyinde; algılanan stres değişkeni pu-anlarının yaşam doyumu puanlarına doğrudan etkisi -,17 düzeyinde gerçekleşmektedir. Kurulan modelde yaşam doyumu değişkeninin toplam varyansının \%12'lik bir kısmı açıklanmaktadır, algılanan stres değişkenin ise toplam varyansının \%13'lük bir kısmının açıklandığı görülmektedir.

İkinci modele ilişkin analiz sonuçları doğrultusunda okul temelli yalnızlık ile yaşam doyumu arasındaki ilişkide algılanan stres değişkeninin kısmi aracı rolü olduğunu söyleyebiliriz. Bu aracı rolün anlamlı olup olmadığını belirlemek üzere yapılan bootstraping analiz sonuçları aşağıdaki tabloda özetlenmiştir.

Tablo 3. Dolaylı etkiye ait bootstrapping analizi sonuçları

\begin{tabular}{|c|c|c|c|c|}
\hline $\begin{array}{l}\text { Aracı değişken/Algılanan } \\
\text { stres }\end{array}$ & & $\% 95$ güven a & tki(düşük & \\
\hline \multirow{2}{*}{$\begin{array}{l}\text { Yalnızlık--->Yaşam } \\
\text { doyumu }\end{array}$} & $\begin{array}{c}\text { Standardize edilmiş dolaylı } \\
\text { etki }\end{array}$ & BOOT S.Hata & BootLLCI & BootULCI \\
\hline &,- 06 & 0,007 &,- 0363 &,- 0081 \\
\hline
\end{tabular}

- $\quad$ Standardize edilmemiş ilişki katsayılarına dayanmaktadır.

Tablo 3 incelendiğinde \%95 güven aralığında okul temelli yalnızlığı, algılanan stres üzerinden yaşam doyumu üzerindeki dolaylı etkisinin .06 olduğu görülmüştür. Dolaylı etkinin anlamlı olup olmadığını belirlemek için tahmin aralıkları incelenmiş ve dolaylı etki tahmin (,0363-,0081) aralığında 0'ın yer almadığı görülmüştür. Bu aralıkta 0 (sıfır) bulunmayışı dolaylı etkinin anlamlı olduğunu anlamına gelmektedir (Shrout ve Bolger, 2002). Başka deyişle okul temelli yalnızlık ile yaşam doyumu arasında algılan stresin kısmi aracılık rolünün anlamlı olduğunu söyleyebiliriz.

\section{TARTIŞMA}

Bu çalışmada çocukların okul temelli yalnızlığı ve yaşam doyumu arasındaki ilişkide algılanan stresin aracı rolünü incelemek amaçlanmıştır. Çalışma bulguları, okul temelli yalnızlığın yaşam doyumu üzerindeki dolaylı etkisinin ve algılanan stresin dolaylı aracılık rolünü göstermiştir.

Araştırma sonuçları incelendiğinde okul değişimi değişkenine göre yaşama doyumu ölçeği puanları ile okul temelli yalnızlık ölçeği puanlarının anlamlı düzeyde farklılaşmadığı görülmektedir. Ancak algılan stres ölçeği puanlarının okul değişimi yapan öğrencilerin lehine olacak şekilde anlamlı düzeyde farklılaşmaktadır. Bu bulgu ile paralel Uluocak (2009) yaptığı çalışmada okul değişimi yaşayan (iç göç nedeni ile) çocuklarda okula uyum sorunu, başarısızlık, kekemelik, tırnak yeme, altını ıslatma gibi davranış ve uyum problemlerinin daha sık yaşandığını bulgulamıştır. Bu durum bize okul değiştiren çocukların yoğun stres altında olduğunu göstermektedir.

Yaşam doyumu puanlarının kız öğrencilerin lehine; algılanan stres ölçeği puanlarının erkek öğrencilerin lehine istatiksel açıdan farklılaştığı görülmektedir. Okul temelli yalnızıı ölçeği puanlarının ise cinsiyet değişkenine göre farklılaşmadığı görülmektedir. Okul çağı çocuklarda yapılan bir araştırmada, erkekler tarafından verilen yaşam doyumu ortalama değerlendirmeler, kızlarınkinden daha düşüktür (Strózik, Strózik \& Szwarc, 2016). Çocukların bakış açısından yalnızlık konusunda yapılan araştırmada kızlar, erkeklerden daha sık olarak depresyon, melankoli gibi duygusal belirtilerden söz etmiştir. Ayrıca öğretmen, ebeveyn vb. yetişkinlerin sevmek yerine cezalandırmayı tercih ettiklerini belirtmişlerdir (Galanaki, 2008). Literatür incelediğinde ise başka çocuklarda yalnızlığın cinsiyete göre farklılaşmadığı (Rotenberg, MacDonald \& King, 2004), ergenlik dönemi ile farklılaşmanın başladığı görülmektedir (Koenig \& Abrams, 1999). Bu bakımdan araştırmada elde edilen bulgu alanyazın ile tutarlıdır.

Araştırmada bir diğer bulgu olan çocukların okula nasıl ulaşım sağladıkları değişkenine göre ise sadece okul temelli yalnızlık ölçeği puanları anlamlı düzeyde farklılaştığı görülmektedir. Bu farklılık ise okula yürüyerek gelenler ile servis ile gelenler arasında

| Kastamonu Eğitim Dergisi, 2020, Vol. 28, No. 3| 
servisle gelenlerin lehine, okula yürüyerek gelenlerle ile araba ile gelenler arasında araba ile gelen grubun lehine anlamlı düzeyde farklılaşmaktadır. Bu durum öğrencinin sosyoekonomik düzeyi ya da sosyal destek ile ilişkilendirilebilir.

SED değişkeni sadece yaşam doyumu ölçeği puanları ile anlamlı düzeyde farklılaşmaktadır. Bu farklılık düşük ile orta grup arasında orta grup lehine, düşük ile yüksek grup arasında yüksek lehine ve orta gelir grubu ile yüksek gelir grubu arasında yüksek gelir grubuna dahil olan öğrencilerin lehine anlam düzeyde farklılaşmaktadır. Seligson, Huebner \& Valois (2003) yaptığı araştrmada, yüksek sosyo-ekonomik seviyedeki ergenlerin yaşam doyumu düzeyleri, düşük sosyo-ekonomik düzeydeki ergenlere göre daha yüksek olduğunu ortaya koymaktadır. Güney Afrika'da yapılan bir araştırmada da çocuklarda yaşam doyumu, düşük ve orta sosyoekonomik düzey ile anlamlı ilişkili olduğu görülmüştür (Raats, Adams, Savahl, Isaacs \& Tiliouine, 2019). Bu durum bize SED arttıkça yaşam doyumunun arttığını göstermektedir (Tuzgöl Dost, 2007).

Araştırmanın temel amacı doğrultusunda ise yaşam doyumu ölçeğinden alınan puanlar ile stres ölçeğinden alınan puanlar arasında negatif yönde, yaşam doyumu ölçeğinden alınan puanlar ile okul temelli yalnızlık ölçeğinden alınan puanlar arasında yine negatif yönde istatiksel açıdan anlamlı bir ilişki bulunmuştur. Algılanan stres ölçeği puanları ile okul temelli yalnızlık ölçeği puanları arasında pozitif yönde istatiksel açıdan anlamlı bir ilişki bulunmuştur. Bu bulgu ile paralel olarak Yaacob, Juhari, Talib \& Uba (2009) yaptığı araştırmada yalnızlık ve stres arasında pozitif ilişki olduğunu ortaya koymuştur. Bozorgpour \& Salimi (2012) yaptığı araştırmada ise yalnızlığın yaşam doyumunun negatif yordayıcısı olması bu araştırma bulgusunu desteklemektedir.

Son yıllarda yapılan araştırmaları incelediğimizde yalnızlık; sosyal anksiyete, akran zorbalığı (Acquah, Topalli, Wilson, Junttila \& Niemi, 2016), depresyon (Lasgaard, Goossens, Bramsen, Trillingsgaard \& Elklit, 2011), akademik performans, bilinçli farkındalık (Rosenstreich \& Margalit, 2015) ,siberzorbalık, özsaygı (Brewer \& Kerslake, 2015), sosyal izolasyon (Holt-Lunstad, Smith, Baker, Harris \& Stephenson, 2015), sosyal medya (Pittman \& Reich, 2016) ile ilişkilendirilmiştir.Yapılan meta-analiz çalışmasında ise yalnızlığı yordayıcı değişkenler ele alınmıştır.Bu değişkenlerden birisi de strestir.Stres ve yalnızlık arasındaki ilişkinin düşük düzeyde olduğu tespit edilmiştir (Mahon, Yarcheski, Yarcheski, Cannella, \& Hanks, 2006). Araştırmanın ergenlik dönemini kapsaması ve çocukluk dönemi ile farklı gelişimsel özellikler göstermesi belirleyici bir faktör olarak görülebilir.

Araştırmada okul temelli yalnızlık ile yaşam doyumu arasındaki ilişkide algılanan stresin aracı rolü incelenerek algılan stresin kısmi aracılık rolünün anlamlı olduğu yapılan analizler sonucunda ortaya konulmuştur. Bu bulguyu destekler nitelikte; Robinson, DiTommaso, Barrett \& Hajizadeh (2013) yaptığı araştırmada, yalnızlık düzeyi arttıkça kişinin yaşam doyumunun azaldığı ve stres düzeyinin arttığı görülmektedir. Literatürü incelediğimizde yalnızlık ve yaşam doyumunun farklı aracı değişkenler ile ele alındığı görülmektedir.

Swami ve arkadaşları (2007), tıp öğrencileri ile yaptığı araştrmada yalnızlık ile yaşam doyumu ve depresyon arasındaki ilişkide genel sağı̆̆ın aracı rolü ortaya konulmuştur.Yalnızlığın; yaşam doyumu, sağlık ile negatif ve depresyon ile pozitif ilişkisi görülmektedir. Kong \& You (2013), kolej öğrencileri ile yaptığı araştırmada sosyal destek ve yaşam doyumu arasındaki ilişkide yalnızlık ve özsaygının aracılık rolü incelenmiştir. Kapıkıran (2013), öğrenciler ile yaptığı araştırmada benlik saygısı ve sosyal desteğin yalnızlık ve yaşam doyumu arasındaki ilişkide aracı rolü incelenmiştir. Çivitci \& Çivitci (2009) ergenler ile yaptı̆̆ı araştırmada ise yalnızlık ile yaşam doyumu arasındaki ilişkide özsaygının aracı rolü incelenmiştir. Yapılan araştırmalarda yalnızlık ile yaşam doyumunun negatif ilişkisi bu araştırmanın bulgularını desteklemektedir.

Çocuğun okul temelli yalnızlık düzeyi ile algılanan stres yaşam doyumunu istatistiksel olarak anlamlı bir şekilde yordamaktadır. Başka bir deyişle; çocuğun okul atmosferi, arkadaşlık, akran ilişkileri ile birlikte sosyal kabulü, okulu benimseyerek sınıf içerisindeki uyumu çocuğun akademik, kişisel, sosyal ve akademik anlamda okuma ve eğitime yönelik tutumunda belirleyici olduğunu söyleyebiliriz. Bu doğrultuda çocuklara yönelik verilecek olan psikolojik danışmanlık hizmetlerinde akran zorbalığını önleme ve akran ilişkilerini geliştirmelerine yönelik psikososyal müdahaleleler ve eğitimler gerekli görülmektedir. Ahmed ve Braithwaite (2004) yaptığı araştrmada zorbalığa maruz kalan mağdur öğrencilerin yalnızlıklarının arttığını ve okuldan uzaklaştıkları, akran ilişkilerinin bozulduğunu ortaya koymaktadır. Furniss (2000)'e göre bu durum sonucunda devamsızlıkların arttığı görülmektedir. Bu durum bize yalnızlığı azaltmaya yönelik olarak müdahalelerin gerekliliğini göstermektedir.

Yalnızlığı azaltmaya yönelik olarak yapılan çalışmalar konusunda gerçekleştirilen meta-analiz çalışmasında; sosyal desteğin arttırılması, sosyal becerilerin geliştirilmesi, sosyal ilişkilerin kurulması için fırsatların sunulması ve uyumsuz sosyal bilişlerin ele alınması müdahale yaklaşımları arasındadır (Masi, Chen, Hawkley, Cacioppo, 2011).

Çocuklarda okul temelli yalnızlık konusunda sını öğretmeninin, akranları tarafından izole edilen, akran ilişkileri geliştiremeyen ya da uyum kuramayan öğrencilerin sınıfa uyumu ve sınıfta birlik sağlanmasına yönelik olarak çalışmalar göstermesine ihtiyaç duyulmaktadır. Psikolojik danışmanlık ve rehberlik öğretmeni ve veli işbirliği bu konuda ön plana çıkmaktadır. Bu konuda gerçekleştirilecek grup çalışmaları çocukların sosyal desteğini artıracak ve sosyal becerilerini geliştirecektir. Okul temelli yalnızlığın stres ve yaşam doyumu ilişkisi göz önüne alındığında bu alanda yapılacak koruyucu/önleyici ve müdahale çalışmalarının önemi artmaktadır.

Sonuç olarak okul temelli yalnızlığın yaşam doyumu üzerindeki dolaylı etkisinin ve algılan stresin kısmi aracılık rolünün anlamlı olduğu görülmektedir. Çocuklarda okul temelli yalnızlık arttıkça algılanan stresin de artacağı ve yaşam doyumunun azalacağı söylenebilir.

\section{ÖNERILER}

Araştırmada ulaşılan bulgular sonucunda öneriler sıralanmıştır: 
- Bu araştırmada çocuklarda okul temelli yalnızlık ve yaşam doyumu arasındaki ilişkide algılanan stresin kısmi aracı rolü olduğu bulgulanmıştır. Bundan sonra yapılacak araştırmada tam aracılık edebileceği düşünülen değişkenler ele alınabilir.

- $\quad \mathrm{Bu}$ araştırma 9-11 yaş arası çocukları kapsamaktadır. Bundan sonraki araştırmalarda okul temelli yalnızlık konusunda özellikle yalnızlık duygularının yoğun yaşandığı ve okuldan uzaklaşmaların arttığı ergenlik döneminde ortaokul ve lise kademelerinde de çalışmalar yapılabilir.

- Bu araştırmada çocukların okul temelli yalnızlık sebepleri olası stres kaynakları (akran ilişkileri, öğretmen tutumu, çekingenlik vb.) üzerinde inceleme yapılmamıştır. Stres kaynaklarının belirlenmesi müdahale yöntemlerinin belirlenmesi ve etkililiğini artıracaktır.

- Bundan sonra yapılacak çalışmalarda çocukların olası stres durumları ile baş etmelerine yönelik olarak müdahaleler ve psikoeğitim programları geliştirilebilir.

\section{KAYNAKÇA}

Acquah, E. O., Topalli, P. Z., Wilson, M. L., Junttila, N., \& Niemi, P. M. (2016). Adolescent loneliness and social anxiety as predictors of bullying victimisation. International Journal of Adolescence and Youth, 21(3), 320-331.

Adams, D. L. (1969). Analysis of a life satisfaction index. Journal of Gerontology, 24(4), 470-474.

Ahmed, E., \& Braithwaite, V. (2004). Bullying and victimization: Cause for concern for both families and schools. Social Psychology of Education, 7(1), 35-54.

Asher, S. R., Hymel, S., \& Renshaw, P. D. (1984). Loneliness in children. Child development, 1456-1464.

Allen, H. A., Peterson, J. S., \& Whipple, S. (1981). Loneliness and alcoholism: A study of three groups of male alcoholics. International Journal of the Addictions, 16(7), 1255-1258.

Altay, D. \& Ekşi, H. (2018, Ekim). Çocuklar için yaşam doyumu ölçeği geçerlilik ve güvenilirlik çalışması. 5 . Uluslararası Eğitim Bilimleri Sempozyumu'nda sunulan tam metin bildiri (ss. 354-362), ìstanbul, Türkiye.

Baker, J. A., Dilly, L. J., Aupperlee, J. L., \& Patil, S. A. (2003). The developmental context of school satisfaction: Schools as psychologically healthy environments. School Psychology Quarterly, 18(2), 206.

Boivin, M., Hymel, S., \& Bukowski, W. M. (1995). The roles of social withdrawal, peer rejection, and victimization by peers in predicting loneliness and depressed mood in childhood. Development and Psychopathology, 7(4), 765-785.

Bozorgpour, F., \& Salimi, A. (2012). State self-esteem, loneliness and life satisfaction. Procedia-Social and Behavioral Sciences, 69, $2004-2008$.

Brewer, G., \& Kerslake, J. (2015). Cyberbullying, self-esteem, empathy and loneliness. Computers in human behavior, 48, 255-260.

Chang, L., McBride-Chang, C., Stewart, S. M., \& Au, E. (2003). Life satisfaction, self-concept, and family relations in Chinese adolescents and children. International Journal of Behavioral Development, 27(2), 182-189.

Çivitci, A.(2014). Illk Ergenlikte Öğrenci Yaşam Doyumu: Okul Psikolojik Danışma ve Rehberlik Hizmetleri Açısından Bir Değerlendirme. Milli Eğitim Dergisi, 44(202), 5-18.

Çivitci, N., \& Çivitci, A. (2009). Self-esteem as mediator and moderator of the relationship between loneliness and life satisfaction in adolescents. Personality and Individual Differences, 47(8), 954-958.

Diener, E. D., Emmons, R. A., Larsen, R. J., \& Griffin, S. (1985). The satisfaction with life scale. Journal of personality assessment, 49(1), 71-75.

DiTommaso, E., \& Spinner, B. (1997). Social and emotional loneliness: A re-examination of Weiss' typology of loneliness. Personality and individual differences, 22(3), 417-427.

Dobson, J. E., Campbell, N. J., \& Dobson, R. (1987). Relationships among loneliness, perceptions of school, and grade point averages of high school juniors. School Counselor.

Dost, M. T. (2007). Üniversite öğrencilerinin yaşam doyumunun bazı değişkenlere göre incelenmesi. Pamukkale Üniversitesi Eğitim Fakültesi Dergisi, 22(22), 132-143.

Ebesutani, C., Fierstein, M., Viana, A. G., Trent, L., Young, J., \& Sprung, M. (2015). The role of loneliness in the relationship between anxiety and depression in clinical and school-based youth. Psychology in the Schools, 52(3), 223-234.

Ernst, J. M., \& Cacioppo, J. T. (1999). Lonely hearts: Psychological perspectives on loneliness. Applied and Preventive Psychology, 8(1), 1-22.

Furniss, C.(2000). Bullying in schools: It's not a crime-is it. Education and the Low, 12 (1), 9-29.

Galanaki, E. P., Polychronopoulou, S. A., \& Babalis, T. K. (2008). Loneliness and social dissatisfaction among behaviourally at-risk children. School Psychology International, 29(2), 214-229.

Galanaki, E. P. (2008). Children's Perceptions of Loneliness. Hellenic Journal of Psychology, (5), 258-280.

Goodwin, R., Cook, O., \& Yung, Y. (2001). Loneliness and life satisfaction among three cultural groups. Personal Relationships, 8(2), 225-230.

Hartup, W. W. (1989). Social relationships and their developmental significance. American psychologist, 44(2), 120.

Hartup, W. W., \& Stevens, N. (1997). Friendships and adaptation in the life course. Psychological bulletin, 121(3), 355.

Holt-Lunstad, J., Smith, T. B., Baker, M., Harris, T., \& Stephenson, D. (2015). Loneliness and social isolation as risk factors for mortality: a metaanalytic review. Perspectives on psychological science, 10(2), 227-237.

Hoyle, R. H., \& Gottfredson, N. C. (2015). Sample size considerations in prevention research applications of multilevel modeling and structural equation modeling. Prevention Science, 16(7), 987-996. 
Hoyle, R. H., \& Smith, G. T. (1994). Formulating clinical research hypotheses as structural equation models: A conceptual overview. Journal of consulting and clinical psychology, 62(3), 429.

Hymel, S., Tarulli, D., Hayden Thomson, L., \& Terrell-Deutsch, B. (1999). Loneliness through the eyes of children. Loneliness in childhood and adolescence, 80-106.

Jones, W. H., Freemon, J. E., \& Goswick, R. A. (1981). The persistence of loneliness: Self and other determinants 1. Journal of personality, 49(1), 27-48.

Kapıkıran, Ş. (2013). Loneliness and life satisfaction in Turkish early adolescents: The mediating role of self esteem and social support. Social Indicators Research, 111(2), 617-632.

Kaya, A. (2005). Çocuklar İçin Yalnızlık Ölçeğinin Türkçe Formunun Geçerlik ve Güvenirlik Çalışması. Eurasian Journal of Educational Research (EJER), (19).

Kemala, I. N.(2017). Loneliness In School: School Counsellor's Perspective About What, Why and How. International E-Journal of Advances in Education, 3(9), 525-533.

Koenig, L.J., \& Abrams, R.F. (1999). Adolescent loneliness and adjustment: A focus on gender differences. In K.J. Rotenberg \& S. Hymel (Eds.), Loneliness in childhood and adolescence, 296-322. Cambridge, UK: Cambridge University Press.

Kong, F., \& You, X. (2013). Loneliness and self-esteem as mediators between social support and life satisfaction in late adolescence. Social Indicators Research, 110(1), 271-279.

Kwok, S. Y., Gu, M. \& Kit, K. T. K. (2016). Positive psychology intervention to alleviate child depression and increase life satisfaction: A randomized clinical trial. Research on social work practice, 26(4), 350-361.

Laine, K. (1998). Finnish Students' Attributions for School-based Loneliness. Scandinavian journal of educational research, 42(4), 401-413.

Lasgaard, M., Goossens, L., Bramsen, R. H., Trillingsgaard, T., \& Elklit, A. (2011). Different sources of loneliness are associated with different forms of psychopathology in adolescence. Journal of Research in Personality, 45(2), 233-237.

Mahon, N. E., Yarcheski, A., Yarcheski, T. J., Cannella, B. L., \& Hanks, M. M. (2006). A meta-analytic study of predictors for loneliness during adolescence. Nursing research, 55(5), 308-315.

Masi, C. M., Chen, H. Y., Hawkley, L. C., \& Cacioppo, J. T. (2011). A meta-analysis of interventions to reduce loneliness. Personality and Social Psychology Review, 15(3), 219-266.

Mellor, D., Stokes, M., Firth, L., Hayashi, Y., \& Cummins, R. (2008). Need for belonging, relationship satisfaction, loneliness, and life satisfaction. Personality and individual differences, 45(3), 213-218.

Natvig, G. K., Albrektsen, G., \& Qvarnstrøm, U. (2003). Associations between psychosocial factors and happiness among school adolescents. International journal of nursing practice, 9(3), 166-175.

Neugarten, B. L., Havighurst, R. J., \& Tobin, S. S. (1961). The measurement of life satisfaction. Journal of gerontology.

Oral, T., \& Ersan, C. (2017). Çocuklarda (8-11 YAŞ) Algılanan Stres Ölçeği'nin Türkçeye Uyarlama Çalışması. Selçuk Üniversitesi Edebiyat Fakültesi Dergisi, (37), 419-428.

Ouellet, R., \& Joshi, P. (1986). Loneliness in relation to depression and self-esteem. Psychological reports, 58(3), 821-822.

Parker, J. G., \& Asher, S. R. (1993). Friendship and friendship quality in middle childhood: Links with peer group acceptance and feelings of loneliness and social dissatisfaction. Developmental psychology, 29(4), 611.

Pavot, W., \& Diener, E. (2009). Review of the satisfaction with life scale. In Assessing well-being(pp. 101-117). Springer, Dordrecht.

Peplau, L. A., \& PerIman, D. (1979). Blueprint for a social psychological theory of loneliness. In Love and Attraction: An Interpersonal Conference, June (pp. 101-110). Pergamon Press, New York.

Pittman, M., \& Reich, B. (2016). Social media and loneliness: Why an Instagram picture may be worth more than a thousand Twitter words. Computers in Human Behavior, 62, 155-167.

Rosenstreich, E., \& Margalit, M. (2015). Loneliness, mindfulness, and academic achievements: A moderation effect among first-year college students. The Open Psychology Journal, 8(1).

Strózik, D., Strózik, T., \& Szwarc, K. (2016). The subjective well-being of school children. The first findings from the children's worlds study in Poland. Child indicators research, 9(1), 39-50.

Swami, V., Chamorro-Premuzic, T., Sinniah, D., Maniam, T., Kannan, K., Stanistreet, D., \& Furnham, A. (2007). General health mediates the relationship between loneliness, life satisfaction and depression. Social psychiatry and psychiatric epidemiology, 42(2), 161-166.

Qualter, P., Brown, S. L., Munn, P., \& Rotenberg, K. J. (2010). Childhood loneliness as a predictor of adolescent depressive symptoms: an 8-year longitudinal study. European Child \& Adolescent Psychiatry, 19(6), 493-501.

Quan, L., Zhen, R., Yao, B., \& Zhou, X. (2014). The effects of loneliness and coping style on academic adjustment among college freshmen. Social Behavior and Personality: an international journal, 42(6), 969-977.

Raats, C., Adams, S., Savahl, S., Isaacs, S., \& Tiliouine, H. (2019). The Relationship Between Hope and Life Satisfaction Among Children in Low and Middle Socio-Economic Status Communities in Cape Town, South Africa. Child Indicators Research, 12(2), 733-746.

Renshaw, P. D., \& Brown, P. J. (1993). Loneliness in middle childhood: Concurrent and longitudinal predictors. Child Development, 64(4), 12711284.

Robinson, B. A., DiTommaso, E., Barrett, Y., \& Hajizadeh, E. (2013). The relation of parental caregiving and attachment to well-being and loneliness in emerging adults. Psychology and Education: An Interdisciplinary Journal, 50(3/4), 19-31.

Rotenberg, K. J., MacDonald, K. J., \& King, E. V. (2004). The relationship between loneliness and interpersonal trust during middle childhood. The Journal of genetic psychology, 165(3), 233-249. 
Russell, D., Peplau, L. A., \& Ferguson, M. L. (1978). Developing a measure of loneliness. Journal of personality assessment, 42(3), $290-294$.

Russell, D., Cutrona, C. E., Rose, J., \& Yurko, K. (1984). Social and emotional loneliness: an examination of Weiss's typology of loneliness. Journal of personality and social psychology, 46(6), 1313.

Salimi, A. (2011). Social-emotional loneliness and life satisfaction. Procedia-Social and Behavioral Sciences, 29, 292-295.

Seligson, J. L., Huebner, E. S., \& Valois, R. F. (2003). Preliminary validation of the brief multidimensional students' life satisfaction scale (BMSLSS). Social Indicators Research, 61(2), 121-145.

Seligman, M. E., \& Csikszentmihalyi, M. (2014). Positive psychology: An introduction. In Flow and the foundations of positive psychology (pp. 279-298). Springer, Dordrecht.

Seligson, J. L., Huebner, E. S., \& Valois, R. F. (2003). Preliminary validation of the brief multidimensional students' life satisfaction scale (BMSLSS). Social Indicators Research, 61(2), 121-145.

Shin, Y. (2007). Peer relationships, social behaviours, academic performance and loneliness in Korean primary school children. School Psychology International, 28(2), 220-236.

Shrout, P. E., \& Bolger, N. (2002). Mediation in experimental and nonexperimental studies: new procedures and recommendations. Psychological methods, 7(4), 422.

Suldo, S. M., Riley, K. N., \& Shaffer, E. J. (2006). Academic correlates of children and adolescents' life satisfaction. School Psychology International, 27(5), 567-582.

Sümer, N. (2000). Yapısal eşitlik modelleri: Temel kavramlar ve örnek uygulamalar. Türk psikoloji yazıları, 3(6), 49-74.

Tezcan, C. (2008). Yapısal eşitlik modelleri. Yayınlanmamış Yüksek Lisans Tezi.

Tuck, W. P. (1981). Book Review: II. Ministry Studies: The Loneliness of Children.

Uluocak, G. P. (2009). İç Göç Yaşamış ve Yaşamamış Çocukların Okulda Uyumu. Dokuz Eylül Üniversitesi Buca Eğitim Fakültesi Dergisi, (26), 3544.

Weeks, M., Coplan, R. J., \& Kingsbury, A. (2009). The correlates and consequences of early appearing social anxiety in young children. Journal of Anxiety Disorders, 23(7), 965-972.

Weiss, R. S. (1973). Loneliness: The experience of emotional and social isolation.

Wenz, F. V. (1977). Seasonal suicide attempts and forms of loneliness. Psychological Reports, 40(3), 807-810.

Vasta, R., Haith, M. M., \& Miller, S. A. (1992). Child psychology: The modern science. John Wiley \& Sons.

Yaacob, S. N., Juhari, R., Talib, M. A., \& Uba, I. (2009). Loneliness, stress, self esteem and depression among Malaysian adolescents. Jurnal Kemanusiaan, $7(2)$.

Yıldırım, i. (2000). Akademik başarını yordayıcısı olarak yalnızlık sınav kaygısı ve sosyal destek. Hacettepe Üniversitesi Eğitim Fakültesi Dergisi, 18(18). 